\title{
Wandering Dhamma and transnational fellowship: Addiction, aspiration and belonging among ethnic minorities on the northern Thai border
}

\author{
Sophorntavy Vorng
}

\begin{abstract}
This article compares Buddhist and Christian approaches to the drug problem among ethnic minorities in northern Thailand. Government programmes implemented through Buddhist monasteries aim to construct Buddhist subjects and realise agendas of national security in border areas. Yet, they also offer development support and access to resources. Meanwhile, gospel rehabilitation centres provide much-needed drug treatment services while drawing highlanders into transnational spheres of Christian fellowship. Consequently, I argue that the relationship between ethnic minorities and the state can be defined in terms of aspiration and negotiation, as well as resistance and evasion, as has been previously argued in the literature.
\end{abstract}

The highland villages and communities of northern Thailand are embedded within the distinctively diverse backdrop of a region that is often argued to transcend the politico-geographic boundaries of conventional area studies paradigms. Referred to variously as the Southeast Asian Massif' ${ }^{1}$ or 'Zomia',2 it is a milieu informed by its long history as a major drug production and trafficking region dubbed by the Central Intelligence Agency (CIA) as 'The Golden Triangle': a rugged, isolated, and politically unstable zone where the modern borders of Myanmar, Thailand, and Lao PDR (Laos) meet. Previous research has examined the themes of legal status and citizenship ${ }^{3}$ as well as the striking phenomenon of widespread religious

Sophorntavy Vorng is a Postdoctoral Research Fellow at the Max Planck Institute for Religious and Ethnic Diversity, Göttingen. Correspondence regarding this article should be addressed to: vorng@ mmg.mpg.de. I would like to thank my colleagues at MPI and the two anonymous JSEAS referees for their helpful comments, criticisms, and suggestions. Thanks also go to the Max Planck Society for funding this research.

1 Turbulent times and enduring peoples: Mountain minorities in the South-East Asian Massif, ed. Jean Michaud (Richmond: Curzon, 2000).

2 Willem van Schendel, 'Geographies of knowing, geographies of ignorance: Jumping scale in Southeast Asia', in Locating Southeast Asia: Geographies of knowledge and politics of space, ed. Paul Kratoska, Henke Schulte Nordholt and Remco Raben (Singapore: Singapore University Press, 2005), pp. 275-307; James C. Scott, The art of not being governed: An anarchist history of upland Southeast Asia (New Haven: Yale University Press, 2009).

3 For just one example, see Mukdawan Sakboon, 'Controlling bad drugs, creating good citizens: Citizenship and social immobility for Thailand's highland ethnic minorities', in Rights to culture: 
conversion among ethnic minority groups in Thailand and other parts of highland Southeast Asia. ${ }^{4}$ My aim in this article is to contribute to this body of research by exploring how we can better understand the intertwinement of religion, marginalisation, and the drug problem along the borders of Chiang Rai, Thailand's northernmost province.

In his influential book, The art of not being governed: An anarchist history of upland Southeast Asia, James Scott characterised the relationship between highlanders and the state in terms of resistance, refuge and evasion. He defines the remote, mountainous region of Zomia as a 'non-state space' in opposition to the dominant, oppressive space of the state, the latter of which in modern times is inexorably encroaching upon the independence of the highlands. Scott also places a strong emphasis on the agency or intentionality of Zomia's hill populations, whom he argues have consciously chosen to escape or avoid state control or expansion through migration into the inaccessible highlands, in a form of 'deliberate and reactive statelessness'. 5

Victor Lieberman highlights the theoretical significance of Scott's formulation in its regionally unifying perspective of Zomia, and its emphasis on the agency of hill peoples. Simultaneously, however, he draws attention to some major flaws in Scott's analyses, such as its weak evidential base, its ahistorical rendering of the Southeast Asian state, and not least, its dependence on explanations focused on lowland dynamics. ${ }^{6}$ Hjorliefur Jonsson adds that the concept of Zomia has an analytical appeal in its intent to challenge conventional area studies divides and urban-rural binaries. At the same time, however, it is open to various reifications that threaten to replicate previous area studies biases. ${ }^{7}$ Bernard Formoso critiques other aspects of Scott's argument, such as Scott's glossing over of the hierarchical nature of some hill societies, the fact that a large proportion of mountain peoples in southwestern China had already been subjected to indirect rule and taxation from the Song dynasty onwards, and the trade and migratory relations between 'centre' and 'periphery', which demonstrated that 'Zomia' was based more on intermixing and linkages than on division. ${ }^{8}$

In light of these issues, the present article attempts to grapple with Jonsson's theoretical challenge of how we can start to go 'beyond Zomia', rather than taking 'either the community or state for granted as an analytical principle; as the driving force of social relations or historical dynamics' ${ }^{9}$ This is particularly significant given the fragmentary nature of state formation in the highlands of mainland Southeast Asia, which

Heritage, language and community in Thailand, ed. Coeli M. Barry (Chiang Mai: Silkworm, 2013), pp. 213-37.

4 Examples include: Nicholas Tapp, 'The impact of missionary Christianity upon marginalised ethnic minorities: The case of the Hmong', Journal of Southeast Asian Studies 20, 1 (1989): 70-95; Cornelia Kammerer, 'Customs and Christian conversion among Akha highlanders of Burma and Thailand', American Ethnologist 17, 2 (1990): 277-91.

5 Scott, The art of not being governed, p. $\mathrm{x}$.

6 Victor Lieberman, 'A zone of refuge in Southeast Asia? Reconceptualizing interior spaces', Journal of Global History 5, 2 (2010): 336-40.

7 Hjorliefur Jonsson, 'Above and beyond: Zomia and the ethnographic challenge of/for regional history', History and Anthropology 21, 2 (2010): 191-212.

8 Bernard Formoso, 'Zomian or zombies? What future exists for the peoples of the Southeast Asian massif?', Journal of Global History 5, 2 (2010): 314-15.

9 Jonsson, 'Above and beyond', p. 208. 
defies binary models that tend to depict the resistance of non-state actors against the state. ${ }^{10}$ Consequently, this article highlights how these dynamics are much more nuanced than a simple juxtaposition between controlling lowland states and defiant Zomian hill populations. ${ }^{11}$

Drawing on fieldwork in northern Thailand from October 2014 to April 2015, ${ }^{12}$ I argue that situating the analysis within the backdrop of drug abuse and trafficking in the Golden Triangle, as well as the pervasive phenomenon of Buddhist and Christian religious conversion among ethnic minorities, provides a productive way to engage with questions of marginality, inclusion, and state control. The two cases presented here were chosen for comparison because they both addressed the regional addiction and trafficking problem, and targeted ethnic minority highlanders in the Chiang Rai area. Additional criteria were the Christian rehabilitation centre's distinctive Chinese-influenced transnationality in contrast to the Buddhist programme's alignment with state-sanctioned policies and agendas.

The Buddhist example focuses upon the work of a charismatic monk, Phra Khruba Nueachai Khosito, abbot of Wat Tham Pa Acha Thong (the Golden Horse Monastery). ${ }^{13}$ Phra Khruba Nueachai is well known for his anti-drug outreach and his proselytising work in the villages along the Thai-Burmese border. This work is modelled after the Thai government's approach of using Buddhist monks and monasteries in the implementation of national integration policies in border areas under the auspices of the Phra Thammacharik ('Wandering Dhamma') programme, which has been running since 1965 and has its headquarters at Wat Srisoda in Chiang Mai. The programme has been variously aimed at assimilation, preventing the spread of communism, gaining the loyalty of ethnic minority peoples in the border regions by converting them to Buddhism, recruiting young men to ordain as novice monks, providing access to formal education, and helping locals to develop new agricultural methods. ${ }^{14}$

10 Peter van der Veer, The value of comparison (Durham: Duke University Press, 2016), pp. 107-29.

11 See also Magnus Fiskesjö's discussion of the place of mining in the history of the central Wa region in reference to agency, autonomy, and state formation, 'Mining, history, and the anti-state Wa: The politics of autonomy between Burma and China', Journal of Global History 5, 2 (2010): 241-64.

12 Field data was gathered through participant observation and interviews at the two centres and in ten ethnic minority villages. Many of the village trips were undertaken as a volunteer with a local, non-faith-based NGO that worked with ethnic minority children, many of whose parents were too heavily addicted to drugs to care for them. Part of the time, I was assisted by an Akha translator. Otherwise, I communicated with informants in Thai.

13 Where appropriate, pseudonyms have been used to protect the identity of informants and their villages and communities. Pseudonyms were not used in the cases of Operation Dawn, or the Golden Horse Monastery and its abbot, due to their easily identifiable characteristics. Thai words have been transcribed in accordance with the revised rules of the Royal Institute's System of Phonetic Transliteration.

14 Somboon Suksamran, Political Buddhism in Southeast Asia: The role of the sangha in the modernisation of Thailand (London: Hurst, 1977); Roland Platz, 'Buddhism and Christianity in competition? Religious and ethnic identity in Karen communities of northern Thailand', Journal of Southeast Asian Studies 34, 3 (2003): 473-90; Olivier Evrard and Prasit Leeprecha, 'Monks, monarchs and mountain folks: Domestic tourism and internal colonialism in northern Thailand', Critique of Anthropology 29, 3 (2009): 300-323. Scholars have observed a similar phenomenon in Burma whereby conversion to the Buddhist religion demonstrates loyalty to the state. See: Mikael Gravers, Nationalism as political paranoia in Burma: An essay on the historical practice of power (Richmond: Curzon, 1999); Yoko Hayami, 'Pagodas and prophets: Contesting sacred space and power among Buddhist Karen in Karen State', 
The Christian example focuses on the Roem Mai ('New Start') Gospel Rehabilitation Centre, located near the Thai-Lao border. In the gospel rehabilitation method of recovery, salvation from addiction is seen to come from the healing powers of the gospel and Christian fellowship. Founded in 1997, the Roem Mai Centre is heavily influenced by Operation Dawn, a global network of Christian rehabilitation centres. In addition to the Roem Mai Centre, there are three other gospel rehabilitation centres operating in Chiang Rai, two of them affiliated with Operation Dawn. Since its establishment in Hong Kong and Taiwan in the early 1980s by Baptist missionaries, the Operation Dawn project has spread globally to India, Nepal, Canada, the United States, Myanmar, and Thailand. All four of these Christian rehabilitation centres provide free or low-cost drug and alcohol treatment to predominantly ethnic minority villagers from all over the Chiang Rai area.

I investigate how these forms of religious engagement shape modes of aspiration and inclusion for ethnic minority people in northern Thailand in ways that complicate the usual narratives of resistance, incorporation, and state control. In other words, I argue that relations between highlanders, the Thai Buddhist nationstate, and transnational Christian networks, are characterised by aspirations for recognition and belonging, as mediated through religious conversion, rather than as (only) resistance towards the Thai authorities and state control in Scott's sense of anarchic, 'deliberate and reactive statelessness' intended to escape the 'oppressions of state-making projects in the valleys'. ${ }^{15}$

My theoretical framework is inspired by Arjun Appadurai's notion of the subaltern 'capacity to aspire', which he characterises as a 'cultural capacity' and 'futureoriented logic of development' in which the economically deprived may 'find the resources required to contest and alter the conditions of their own poverty'. ${ }^{16}$ As Appadurai argues, theorising aspiration in such a way provides a way to overcome the long-standing opposition between 'culture' and 'development', in which 'culture' is relegated to the realm of tradition and the past, as opposed to the 'future'-oriented conceptualisation of 'development'. Appadurai further elaborates that the capacity to aspire is a 'navigational capacity' which is unequally distributed between the more and less privileged members of society, with the consequence that 'relative poverty means a smaller number of aspirational nodes and a thinner, weaker sense of the pathways' - in short, a 'more brittle horizon of aspirations' ${ }^{17}$ Such an approach is also helpful insofar as it offers the possibility of addressing the overemphasis in studies of the highlanders of Zomia to 'limit their perspective to upland communities of the past'. ${ }^{18}$

Formoso provides a practical understanding of the ways that ethnic minorities negotiate their relationships with the states in which they are embedded, suggesting that:

Journal of Asian Studies 70, 4 (2011): 1083-105; Alexander Horstmann, 'Humanitarian crisis, religious nationalism and religious competition: Buddhist and Christian Karen in the Thai-Burmese borderland', Encounters 4 (2011): 191-213.

15 Scott, The art of not being governed, pp. ix-x.

16 Arjun Appadurai, 'The capacity to aspire: Culture and the terms of recognition', in Culture and pub-

lic action, ed. Viyajendra Rao and Michael Walton (Stanford: Stanford University Press, 2004), p. 59.

17 Ibid., p. 69.

18 Formoso, 'Zomian or zombies?': 316. 
Hill peoples develop relationships with lowland state societies that are more complex and ambiguous than usually portrayed ... political and religious acculturation by lowland societies sometimes proves to have been instrumental in the perpetuation of a specific identity under the guise of surface assimilation ... hill peoples often take advantage of new forms of partnership resulting from globalisation to renegotiate their image and status more favourably, and to counter the pressure exerted by the dominant society. ${ }^{19}$

Illustrating with the example of the Mien in northern Thailand, Jonsson observes that although strategies that emphasise village identities - mainly through sports competitions - render the Mien accessible to certain forms of state control, they also allow Mien communities to position themselves within the sphere of official recognition, thereby allowing access to various benefits and protection. ${ }^{20}$

In the present context, I argue that in the Buddhist sphere, 'negotiation' and 'aspiration' entails working within the bounds of the nation-state's assimilation and integration policies as not merely a form of submitting to state control, but as a pathway to pursuing aspirations through access to education, recognition, and social support. In the Christian domain, this involves engaging with transnational religious projects in order to obtain much-needed addiction treatment at a minimal cost. The latter is something which is out of reach for many ethnic minority people who lack legal citizenship status in Thailand and hence, access to state-subsidised addiction treatment services. At the same time, however, I do not suggest that transnational networks offer a simple pathway to circumventing marginalisation. Similarly, Thai national integration projects, as pointed out by Mukdawan Sakboon, are contradictory in nature, offering possibilities for inclusion, while at the same time circumscribing them. ${ }^{21}$

\section{Inequality, marginality, and addiction}

During my visits to an Akha village called Ban Namsai, located on Doi Fa mountain to the northwest of Chiang Rai, I would often spot 74-year-old Api sitting cross-legged on the ground with the other Akha grandmothers along the narrow path connecting Ban Namsai with the nearby waterfall and tea plantation. As she sits, Api squints through her glasses and painstakingly sews beads and shells onto cotton string to make bracelets, or weaves colourful patterns onto bags and belts. The finished product will be displayed on a cloth in front of her along with the other accessories and trinkets she has made, in the hope that it will catch the eye of one or another trekker as they march by under the watchful eye of their guide, wielding makeshift bamboo hiking poles and sweating profusely in the stifling humidity. The picture is postcard perfect, down to Api's betel-stained teeth, colourful clothes, and ready laugh, an image that has been reproduced countless times in the tourist-oriented literature to depict the tranquil nature of life in the remote mountain villages on Thailand's border.

20 Hjorliefur Jonsson, Mien relations: Mountain people and state control in Thailand (Ithaca: Cornell University Press, 2005), p. 129.

21 Sakboon, 'Controlling bad drugs', pp. 213-37. 
Api's life story lurks behind this idyllic-seeming surface. In my chats with her, she revealed that she was dependent for many years on opium, heroin, and the methamphetamine pill yama. ${ }^{22}$ Her daughter and son-in-law were also addicts. Around fifteen years ago, Api's pregnant daughter was diagnosed with HIV, as was her partner. Both succumbed to AIDS when the child was just an infant, leaving Api as the sole caretaker for her granddaughter. Fortunately, the virus was not transmitted to the baby. After her daughter and son-in-law died, Api managed to quit drugs and supported herself and her now-teenage granddaughter on her meagre income of around 1,000 baht per month. Her husband is long dead and her shelter is dilapidated. Having never been formally educated, Api also sometimes works as a day labourer in order to make ends meet and support her granddaughter's education.

Stories such as that of Api and her granddaughter, in which poverty, drugs, and HIV-AIDS intersect, are not uncommon. ${ }^{23}$ Hence, while the verdant mountain setting draws visitors for its spectacular scenery, to step inside the quaint-looking bamboo huts that serve as shelter for the most disadvantaged villagers is to see a very different picture emerge. Foul-smelling rivulets of water ooze underfoot because there is no plumbing, and rags and rubbish lie in discarded piles on the mud floor or on dusty mattresses. Smoke from wood-fire stoves chokes the air. Infants blink listlessly in makeshift hammocks, rocked by blank-eyed siblings with dirt-streaked faces barely older than themselves. Parents are often absent, labouring in the fields, plantations, factories, construction sites, restaurants, hotels, gas stations, and in other menial roles in Chiang Rai city or further afield in Chiang Mai or Bangkok. ${ }^{24}$ Outside the tourist 'bubble' 25 of colourful costumes and exotic languages and cultural customs, the situation for many ethnic minority people in Chiang Rai and other parts of northern Thailand is a dire one.

High rates of addiction are an increasingly observed feature of uneven transitions to neoliberal capitalist modernity and incorporation within the nation-state. For instance, Shao-hua Lui's research among the Nuosu in Sichuan province in southwestern China traces a connection between urban labour migration, the transition to modernity, and heroin consumption and addiction among young Nuosu men. ${ }^{26}$ Giulia Zoccatelli's study of the heroin epidemic among large numbers of youth in

22 Yama is the original name for yaba. Yama literally translates as 'horse drug'. In July 1996 Thai authorities changed the name from yama, which has connotations of enabling the user to work tirelessly as a horse, to yaba, or 'crazy drug', in order to convey to the public the drug's harmful effects. Bertil Lintner and Michael Black, Merchants of madness: The methamphetamine explosion in the Golden Triangle (Chiang Mai: Silkworm, 2009), p. 2.

23 Upon the onset of the HIV epidemic in Thailand in the late 1980s, the occurrence of the disease was highest in northern Thailand, with most cases concentrated in Chiang Rai province. Tawatchai Keereekamsuk, Sukhum Jiamton, Sutthi Jareinpituk and Jaranit Kaewkungwal, 'Sexual behaviour and HIV infection among pregnant hilltribe women in northern Thailand, Southeast Asian Journal of Tropical Medicine and Public Health 38, 6 (2007): 1062.

24 Some observers have suggested that the subsequent return of the women and girls to villages spurred drug addiction and HIV-AIDS epidemics in villages throughout the region. Cornelia Kammerer and Patricia Symonds, 'AIDS in Asia: Hill tribes endangered at Thailand's periphery', Cultural Survival Quarterly 16, 3 (1992): 23-5.

25 Erik Cohen, 'Toward a sociology of international tourism', Social Research 39, 1 (1972): 164-82.

26 Shao-hua Lui, Passage to manhood: Youth migration, heroin, and AIDS in southwest China (Stanford: Stanford University Press, 2010). 
Qilin city in Yunnan province, in southern China, shows similar factors to be involved, including lack of employment and study opportunities leading to labour migration, increased financial independence, weakening kinship ties, and the individualisation of ambitions and desires. ${ }^{27}$

These examples share some striking similarities with the situation in northern Thailand, where the history of opium production by highland ethnic minorities remains a core part of the region's identity today. Opium was officially outlawed at the end of 1958 in Thailand. However, as a result of crop eradication efforts, the pattern of drug usage in the region changed from opium smoking, to heroin injection, to an escalation in amphetamine-type stimulants (ATS) abuse in the late 1990s. ${ }^{28}$ Some observers suggest that the transition from opium to heroin was the result of aggressive marketing efforts on the part of traffickers, as well as what has been described as a pervasive sense of hopelessness and oppression amongst highlanders. ${ }^{29}$

Today, the main market for ATS is Thailand, with usage spreading across the rest of Southeast Asia and China. ${ }^{30}$ As both a recreational and labour drug, methamphetamine abuse cuts across demographic boundaries, with users ranging from manual labourers to hard-partying urban socialites and teenagers. The latter are targeted by producers through the manufacturing of yaba pills in bright colours and candy flavours. Chris Lyttleton and Anjalee Cohen both report on the significance of yaba consumption as a mode of engagement in modern, capitalist and consumer-oriented society. Among the Akha in Laos, Lyttleton suggests that ATS became a 'symbol of a social ethos geared to increased production, money income and a consumer culture oriented to the pursuit of pleasure through purchase'. ${ }^{31}$ Similarly, Cohen observes that in Chiang Mai, 'with increased leisure time and spending power, yaba - like music and fashion - became another global commodity for consumption and a lifestyle

27 Giulia Zoccatelli, 'It was fun, it was dangerous: Heroin, young urbanities and opening reforms in 1980s China's borderlands', International Journal of Drug Policy 25, 4 (2014): 762-8.

28 Pierre-Arnaud Chouvy and Joel Meissonier, Yaa-baa production, traffic and consumption of methamphetamine in mainland Southeast Asia (Singapore: Singapore University Press; Bangkok: IRASEC, 2004). For a discussion of a shift in Hong Kong from opium to heroin and later, 'club drugs' such as ketamine and ecstasy, as a result of a post-Second World War opium prohibition, see Karen A. Joe-Laidler, 'The rise of club drugs in a heroin society: The case of Hong Kong', Substance Use and Misuse 40, 9-10 (2005): 1257-78. A similar occurrence was observed as a result of British prohibition of opium in nineteenth and early twentieth-century mainland China, which resulted in the transformation of drug culture from that of opium used mainly for recreational and medicinal use, to the consumption of far more harmful drugs such as heroin, morphine, and cocaine; see Frank Dïkotter, Lars Laamann and Xun Zhou, Narcotic culture: A history of drugs in China (Chicago: University of Chicago Press, 2004). 29 Deleu Choupah and Marianne Naess, 'Deleu: A life history of an Akha woman', in Development or domestication: Indigenous peoples of Southeast Asia, ed. Don McCaskill and Ken Kampe (Chiang Mai: Silkworm, 1997), pp. 183-204; Rita Gebert and Chupinit Kesmanee, 'Drug abuse among highland minority groups in Thailand', in ibid., pp. 358-97, and Cornelia A. Kammerer, 'The Akha of the Southwest China borderlands', in Endangered peoples of Southeast and East Asia, ed. Leslie E. Spongel (Westport, CT: Greenwood, 2000), pp. 37-53, as cited by Chris Lyttleton, 'Relative pleasures: Drugs, development, and modern dependencies in Asia's Golden Triangle', Development and Change 35, 5 (2004): 922-3.

30 Chouvy and Meissonnier, Yaa-baa production, traffic and consumption; Lintner and Black, Merchants of madness.

31 Lyttleton, 'Relative pleasures': 916; see also Paul Cohen and Chris Lyttleton, 'Opium reduction programmes, discourses of addiction and gender in northern Laos', Sojourn 17, 1 (2002): 1-23. 
choice for many young Thai' ${ }^{32}$ Although Lyttleton and Cohen documented the phenomenon of yaba consumption in Laos and Chiang Mai, the problem appears to have become pervasive in Chiang Rai, as well.

For instance, in one small Lahu village, the staff of the local NGO with which I volunteered estimated up to 90 per cent of villagers, from pre-teen youths to elderly women, to be addicted to yaba. There, we often went to visit an elderly Lahu woman, and her grandchildren. Just metres away from their bamboo hut was a ramshackle drug den, holes in the walls patched with rotting wood and faded cloth, which we observed to have a steady flow of visitors, causing the NGO workers to dub it 'Seven-Eleven', after the 24-hour convenience stores found all over Thailand. Keeping the children away from such negative influences was a constant challenge, especially given the dearth of good prospects. One of the Lahu woman's grandsons, 18-year-old Jado, had graduated from secondary school and was now working as a petrol station attendant in Chiang Rai city. Although he only earned a minimum wage ( 300 baht per day at the time of writing), she was proud that he was holding down a steady job, paying off his own motorcycle, and saving enough money to help support her and his siblings. She hoped the same for her younger grandson, who was now 14 years old and living with a foster family closer to his school so that he could attend classes more regularly.

We also came across a number of cases in the same village in which children were regularly exposed to the drug use of parents or other villagers. Pen, one of the NGO staff who worked in the village, recalled one occasion when she visited the home of one of the children sponsored by her organisation. As she interviewed the mother about the child's health and educational progress, the woman had prepared and smoked yaba in full view of Pen and her son and daughter. Pen remarked, 'I was shocked. She did not try to hide it at all. How can the children's lives improve when such things are considered normal?' Aside from the potential harm from exposure to drugs, when parents are addicts, the nutrition and education of the children can be neglected, as a consequence of the channelling of scarce finances towards the purchase of drugs. One couple we spoke with reported earning 3 to 5 baht per kilo for the banana leaves that they collected from the forest to sell to a shop in Chiang Rai city. They had four children, the youngest only a few months old. Both parents were yaba addicts, and spent a large proportion of their income on methamphetamine pills, leaving little to spare for the children.

The lack of citizenship has been seen as a root cause underlying exclusion and marginalisation among highlanders, having a deep impact on both physical and social mobility, educational and employment opportunities, and access to human rights. ${ }^{33}$ While Thai citizenship is no longer a prerequisite for access to education, many minority youths are unable to complete secondary or vocational school as their families cannot afford their education, or because they live too far away from the nearest school. Even with a certain level of education, they may face obstacles to employment due to intense competition and the negative stereotyping of highlanders in Thai

32 Anjalee Cohen, 'Crazy for ya ba: Methamphetamine use among northern Thai youth, International Journal of Drug Policy 25, 4 (2014): 778.

33 Sakboon, 'Controlling bad drugs'. 
society. These factors often result in highlanders being passed over in favour of equally or less-qualified ethnic Thai. For instance, one Lahu law graduate I interviewed was working as a masseur alongside his mother (who had never been formally educated) as a result of not being able to find appropriate employment. The head of an NGO in Chiang Rai which specialised in supporting Akha students gain vocational skills confirmed that this was not uncommon. With the increasing number of graduates each year, competition for employment in the urban centres was intense.

Among the young people with whom I spoke, I found a widespread sense of disillusionment from being unable to find appropriate employment. This was often linked with feelings of being ethnically discriminated against. For instance, I would often see 18-yearold Ayong drifting around aimlessly, sitting in front of his house or near the local guesthouse, sometimes with a beer in his hand. Ayong had completed the third level of secondary school (mathayom), which in Thailand constitutes the final year of compulsory basic education, and is the prerequisite for most types of unskilled employment. He lived with his family in an Akha village to the northwest of Chiang Rai. Some of his friends had found work at construction sites or doing menial jobs in the city. When I asked him why he did not go to find work with the others, he responded dismissively that he was content to be unemployed since he liked the freedom and lack of obligation. I followed up by asking him if discrimination made it difficult for him to find work. He responded somewhat defensively that it was not a problem. However, another young man who was a friend of Ayong's, and who had been observing the discussion from close by, interjected:

Yes, it is a problem - they see that we are chao khao ['hill tribe' ethnic minority people] and they look down on us. They think we can't do good work or that we're dishonest. It makes us feel bad. So sometimes, because of this, we don't even want to try.

Many of the villagers who did manage to find work reported that they were employed as day labourers (khon rap chang). Working as a day labourer is one of the few options available to the many highland ethnic minority people without the legal status, educational qualifications, vocational skills, or opportunities to engage in conventional employment. It is economically precarious, and often, extremely physically demanding work. As one Akha villager stated,

There's no job security, we have to survive whatever way we can with whatever work we can find. Every day when the children go to school it costs money. Everything costs money. We have to support our family but we don't have our own land. Then when things get stressful, people take drugs as a way out, as an escape.

Hence, in addition to reports of drug use as both a pleasurable activity and as a form of relief from financial and personal stress, yaba consumption was seen as a way for tired bodies to withstand the intense physical demands of the hard labour that is crucial to their economic survival. The phenomenon has been reported by journalists among jade miners addicted to heroin in Myanmar's Kachin state, ${ }^{34}$ and rubber

34 Jonah Kessel, 'The life and times of an addict in Myanmar', New York Times, 2 Dec. 2012; Al Jazeera, 'Myanmar's jade curse', 101 East, 3 Dec. 2014, http://www.aljazeera.com/programmes/101east/ 2014/11/myanmar-jade-curse-201411249233318531.html (last accessed 3 Dec. 2014). 
plantation workers addicted to yaba in northeastern Thailand. ${ }^{35}$ In Laos, Lyttleton reports that Akha labourers were paid in methamphetamines as well as cash and opium for labouring in the rice fields or in construction projects. ${ }^{36}$ In another study on young underclass men in a Philippine port, Gideon Lasco reports that methamphetamine served as an important performance enhancer that allowed for a greater chance of success in the competitive informal economy. ${ }^{37}$ All these contexts have in common the predicament of low-income earners in precarious economic situations, who must stretch their bodies to the limit in order to make ends meet. In Thailand, state authorities have attempted to fill the socioeconomic gaps left by opium eradication and limited employment opportunities by introducing a range of alternative development programmes. Unfortunately, these have not proven to be the hoped-for panacea for what continues to be an intractable problem.

\section{Pitfalls of alternative development}

As Thongchai Winichakul argues, the ethno-spatial discourse surrounding state-run development projects is based on the hierarchical differentiation of 'civilised' Bangkok-based elite positioned in modernity and the future-oriented present, from two inferior categories of 'Others within', positioned in the remote and premodern past: multi-ethnic chao bannok (lowland, rural villagers), and chao pa (forest/wild people). The category of chao pa later shifted into the closely related category of chao khao, which constructed mountain peoples as dangerous, opium-producing Others only rendered less threatening through the civilising and modernising processes of commodification, development, and tourism. ${ }^{38}$ Jonsson similarly observes that 'notions of civility and hierarchy were central to the consolidation of lowland society and the mapping of its opposite on the forested mountains'. ${ }^{39}$

Hence, in the 1970s and 1980s, the Thai government began introducing alternative cash crops in an effort to foster development in the region and combat what the state perceived as the growing drug and communist insurgency problem. ${ }^{40}$ The most prominent alternative development campaign is the Royal Project, a state-run initiative that began in 1984, and which subsidises the irrigation, packaging and transportation of fresh produce grown by highland farmers. Through the Royal Project's chic, glossy shop fronts, this produce is sold - at rather inflated prices - to affluent middle and upper-class Thais and expatriates in shopping malls in Bangkok, Chiang Mai, and other urban centres around Thailand. The Royal Project's marketing strategy is

35 Lizzie Presser and Fabian Drahmoune, 'Drug addiction grows on Thai rubber farms', Al Jazeera, 1 Dec. 2014, http://www.aljazeera.com/indepth/features/2014/11/drug-addiction-grows-thai-rubberfarms-2014113074454777879.html (last accessed 1 Dec. 2014).

36 Lyttleton, 'Relative pleasures': 928.

37 Gideon Lasco, 'Pampagilas: Methamphetamine in the everyday economic lives of underclass male youths in a Philippine port', International Journal of Drug Policy 25, 4 (2014): 783-8.

38 Thongchai Winichakul, 'The Others within: Travel and ethno-spatial differentiation of Siamese subjects, 1885-1910', in Civility and savagery: Social identity in Tai states, ed. Andrew Turton (London: Curzon, 2000), pp. 38-62.

39 Jonsson, Mien relations, p. 17.

40 Chayan Vaddhanaphuti, "The Thai state and ethnic minorities: From assimilation to selective integration', in Ethnic conflicts in Southeast Asia, ed. Kusuma Snitwongse and Willard Thompson (Singapore: Institute of Southeast Asian Studies; Bangkok: Institute of Security and International Studies, Chulalongkorn University, 2005), pp. 151-66. 
based on providing consumers with the assurance that their patronage of the store directly contributes to 'saving the hill tribes' from their nefarious, uncivilised, opiumgrowing past, and bringing them into sync with the modern market economy. Doi Thung, another state-run project, markets products such as coffee, macadamia nuts, and handicrafts. Taking centre stage at its stores is a United Nations Office on Drugs and Crime (UNODC)-endorsed sign, which declares that any purchase will contribute to 'the achievement of a drug-free world'.

In addition to Doi Thung and similar programmes, there are an increasing number of trendy cafes hawking locally grown Arabica coffee and numerous varieties of tea direct from the mountains. All such ventures, whether government driven or privately owned, operate on the same principle of replacing a 'backwards', illegal, cash crop with commodities that align more closely with the imperatives and identity of the modern capitalist nation-state. Yet, in spite of these initiatives, studies have shown that crop eradication and the lack of viable economic alternatives have had a detrimental effect on communities in the region, and led to greater poverty and inequality. Among the Akha in northwestern Laos and northern Thailand, Lyttleton found that the tension between cultural differences and national development led to a number of social disjunctions, including large-scale migration to urban centres, widespread uptake of heroin and ATS, engagement in sex work, and epidemics of HIV-AIDS and malnutrition. ${ }^{41}$ In another study, Kathleen Gillogly shows how opium interdiction profoundly changed the nature of social relations among the Lisu in northern Thailand. Combined with the increased availability of heroin, addiction rates among young Lisu men increased dramatically. ${ }^{42}$

At one Lahu village, where the villagers were owner-operators of coffee, fern, and vegetable plantations, my informant confirmed that involvement with the Royal Project had been a positive source of development in that particular village, although there were many other villages where such projects had started off well before deteriorating due to mismanagement or conflict. ${ }^{43}$ Another Akha man revealed to me that at a well-known coffee-growing mountain towards the south of Chiang Rai, the villagers had banded together to create a company through which they had borrowed, in his estimation, more than 700 million baht from the bank. However, rather than channelling the funds towards expanding the business, he reported that people used the money to buy expensive cars and build large houses, with some mansions on the mountain being worth at least 3 or 4 million baht. In his view, the advantages of the increased flow of cash were of an ambivalent nature, leading to the emergence of intense material competition and conflict between friends and neighbours.

To say that blotting out the opium fields did little to solve Thailand's drug problem is a major understatement. Initiatives such as the Royal Project and others like it are lauded as hugely successful examples of crop substitution campaigns and used as

41 Lyttleton, 'Relative pleasures'.

42 Kathleen Gillogly, 'Opium, power, people: Anthropological understandings of an opium interdiction project in Thailand', Contemporary Drug Problems 35, 4 (2008): 704.

43 Thailand continues to enforce strict lèse majesté laws criminalising perceived defamation of the monarchy. Such laws prevent informants from openly discussing or critiquing royally sanctioned projects. 
models for alternative development interventions in other contexts. ${ }^{44}$ Yet, while many ethnic minority people are involved in these economic networks to one extent or another, whether as labourers in the fields, investors with a stake in the businesses, or as trekking guides, guesthouse owners, or hospitality workers, the advantages of the alternative development projects have been uneven, failing to reach individuals and communities equally. Instead, the evidence suggests that incorporation into modern economic networks has exacerbated, rather than alleviated, the drug problem in its various guises - not least in terms of placing the burden on wage labourers to perform competitively in the capitalist market by creating a situation in which methamphetamine use and abuse is perceived as a necessary evil in order to survive economically. Not least, crop eradication efforts and alternative development programmes fail to address the ongoing political instability and ethnic tensions within the region, which, combined with high-level corruption and sophisticated transnational trafficking networks, are the major drivers of the local and global drug trade. ${ }^{45}$

Ex-prime minister Thaksin Shinawatra's controversial 2003 'war on drugs' was another strategy that failed to address the fundamental causes of the drug problem, resulting instead in over 2,500 extrajudicial killings and the incarceration of low-level, predominantly ethnic minority, traffickers and drug dependents. ${ }^{46}$ The majority of deaths occurred in northern Thailand, with authorities blaming inter-gang warfare for the high number of killings. ${ }^{47}$ Some of the long-term effects of the violent campaign were evident in the discomfort expressed when I raised the topic of drugs in highland villages with informants. Some limited their answers to admitting that there had been problems in the past, which had since been eradicated. Others preferred to deny the existence of drug problems in their communities altogether, even when it was clearly obvious that this was not the case. ${ }^{48}$ The Thai government has also implemented anti-drug and border security initiatives through softer campaigns, aimed at inculcating political loyalty in ethnic minorities. Next, I examine one of these programmes, focusing on the work of Phra Khruba Nueachai and his disciples at the Golden Horse Monastery in Mae Chan.

\section{Golden Horse Monastery: Constructing loyal Buddhist subjects}

Known in Thailand as phra khima binthabat, or literally, 'monks who ride horses to collect alms', the unconventional Golden Horse Monastery and its abbot have become widely known through a 2003 Tourism Authority of Thailand (TAT) campaign lauding it as one of the treasures of 'Unseen Thailand', as well as through a

44 United Nations Office on Drugs and Crime (UNODC), Alternative development: A global thematic evaluation. Final synthesis report (New York: United Nations, 2005); UNODC, 'Thai alternative development projects showcased at international workshop', http://www.unodc.org/ southeastasiaandpacific/en/2011/12/alternative-development-chiang-mai/story.html (last accessed 20 Feb. 2016). See also the Highland Research and Development Institute (HRDI) website, http://www. hrdi.or.th/en/what_we_do/page/Our-Success (last accessed 20 Feb. 2016).

45 Lintner and Black, Merchants of madness; Pierre-Arnaud Chouvy, Opium: Uncovering the politics of the poppy (Cambridge, MA: Harvard University Press, 2011).

46 Alex Mutebi, 'Thailand in 2003: Riding high again', Asian Survey 44, 1(2003): 78-86.

47 Lintner and Black, Merchants of madness, p. 6.

48 Due to space limitations, I am unable to address Thaksin's 'war on drugs' in detail in this article. A forthcoming article will investigate the topic in further depth. 
documentary by Dutch film-maker Mark Verkerk. The monastery is extremely popular with Thai amulet enthusiasts hoping to capture the potent charisma, or barami, of its abbot, a former champion muai Thai boxer who is surrounded by tales of invincibility and strength in the face of attacks by knife, gun, and poison-wielding assailants - including henchmen of the Burmese drug lord Khun Sa himself.

Rather than being a drug rehabilitation facility, the core of Phra Khruba Nueachai and his disciples' work consists of outreach, and anti-drug and development work with Lahu, Lisu, Akha, Yao, and other ethnic minority communities in the border regions. Much of this work is performed in the Mae Chan and Mae Fah Luang districts through approximately twelve outreach temples undergoing reconstruction and renovation. Financial support for the monastery and its projects comes from donations from Phra Khruba Nueachai's disciples and lay supporters, the general public, and the Royal Thai Army. The sale of amulets and other sacred paraphernalia provides an additional source of income. The monastery's activities centre on four main projects under the official patronage of the Thai Sangha Council's Supreme Patriarch. These include reforestation initiatives and conservation of horse breeds. Here, I narrow my analysis to the aspects of the monastery's programmes that focus on Buddhist proselytisation and the cultivation of Buddhist Thai identity.

As part of the 'saint of the mountain' project (khrongkan nakbun haeng khun$k h a o$ ), teams of monks and novices from the monastery travel long distances on horseback to reach remote ethnic minority communities along the Thai-Burmese border, with the aim of encouraging loyalty to the Thai nation through the propagation of Buddhism. As Roland Platz points out in relation to the Phra Thammacharik programme, 'more important than teaching Buddhism, these teams taught that becoming a good Thai citizen meant to love the King and the nation'. ${ }^{49}$ Monks are also based at remote border outposts for months at a time in order to familiarise themselves with local minority communities and to proselytise. These activities are conducted in conjunction with the 'sending warmth into the mountains' project (khrongkan mop ai un su khunkhao), which provides ethnic minority villagers with food, blankets, clothing, medicines, educational resources, and other essential provisions and supplies.

The monastery also provides humanitarian assistance to villages in the area affected by flooding, storms, fire, and other natural disasters. In addition, Phra Khruba Nueachai and his disciples encourage Buddhist activities in the area through the construction and renovation of temples along the Thai-Burmese border, spread through the subdistricts of Mae Salong Nai, Thoet Thai, Khun Kon, and Sri Kham. The project also involves an educational campaign and the development of villagers' vocational skills for the purpose of protecting the environment and conserving natural resources. Another significant sphere of activities undertaken by the monastery is the 'ordination project and training camp for moral and ethical behaviour' (khrongkan buat oprom khai khunatham chariyatham). The main aim of the project is to instil a sense of moral virtue, Thai culture, and responsibility towards the Thai nation.

According to Luang Phi To, one of the senior monks at the monastery, a central focus of their work revolves around nurturing the hearts and minds of ethnic

Platz, 'Buddhism and Christianity in competition?', p. 476. 
minority youths, so that they would have - through their loyalty and connection to Phra Khruba Nueachai and, by extension, the Thai nation-state - the strength and determination to stay away from drugs. During the annual training camp, several dozen boys and young men are ordained as novices or monks, and reside at the monastery. The youths attend workshops facilitated by soldiers and monks on the dangers of abusing and trafficking in drugs, and the principles of being a good Buddhist and Thai citizen, or participate in activities such as caring for horses, training in muai Thai, Buddhist scripture, and meditation classes. Some of the youths stay for a few days, while others stay for a week or a month or more. A few, typically those who come from troubled backgrounds - those who are abandoned by their families, whose parents cannot afford to care for them, who are orphaned or whose parents are in prison, usually in connection with drugs - will stay permanently, and are taught the Thai language and other basic skills by volunteers.

With the strong presence of government and army officials alongside the Buddhist monks conducting religious processions and merit-making activities, the mass ordination and training camp at the monastery bears strong parallels to a fun fair described by Jonsson which took place at a school in Pangkha during Mien New Year festivities, during which 'various manifestations of national order' took place that 'constituted a ritualised act of allegiance to the modern nation-state'. ${ }^{50}$ Although ethnic minority culture and identity were showcased at the fair, it was framed in ways which 'were orderly, nationalist, presentable to a generalised Thai audience, and fun to visit - the opposite of the Thai stereotype of disorderly and destructive chao khao'. ${ }^{51}$

Additionally, the late Isan anthropologist Pattana Kittiarsa argued that ordination into monkhood is seen as the Buddhist ideal for Thai men. Muai Thai is an embodiment of masculine national Thai identity; its protective powers are closely related to the literal and symbolic safeguarding of Buddhism and the Thai nation. Based on an analysis of the 2003 hit film Ong Bak: Muai Thai warrior, Kittiarsa observed that 'muai Thai is Thailand's true national heritage, culturally woven into delicate tissues of the country's national tri-pillars: nation, religion (read Buddhism), and monarchy ... its real existence is to protect the pillars of "Thai-ness" against intruding enemies'. ${ }^{52}$ These enemies of the Thai nation are embodied in (global) social problems such as gambling, drugs, and prostitution, which erode Thai Buddhist cultural values. ${ }^{53}$ For the youths involved in the programme, muai Thai practice is presented as building character, strength, and self-esteem. This ultimately helps to build an aversion to the 'national enemies' of drug abuse, engaging in the drug trade as a means to earn income, or associating with traffickers, thereby keeping the country, religion, and monarchy safe.

The work of Phra Khruba Nueachai and the Golden Horse Monastery can be viewed on the one hand as an extension of the traditional social function of monasteries in Thailand, which have long served as places of moral and formal education,

50 Jonsson, Mien relations, p. 109.

51 Ibid., pp. 109-10.

52 Pattana Kittiarsa, 'Faiths and films: Countering the crisis of Thai Buddhism from below', Asian Journal of Social Science 34, 2 (2006): 276.

53 Ibid.: 278. 
where men and youths from troubled backgrounds are sent to stay in a structured and disciplined environment, away from negative influences back at home. In the past, it was also one of the only ways that youths of low socioeconomic status could access formal education. On the other hand, it can also be seen as another instance of the Thai state's co-opting of the sangha, as well as the charisma of influential monks, in order to bolster its own sanctity and legitimacy in line with the construction of Buddhism, monarchy, and the nation, as the three pillars of Thai nationalism. ${ }^{54}$ Such strategies serve as attempts to bolster national security and subdue illicit, drug-related activity in border areas, where ethnic minority peoples have long been saddled with negative stereotypes as opium growers, drug addicts, and narcotics traffickers - even as the Thai government ignores the underlying causes of these social issues in contradictory state policies which often exacerbate their marginalisation and exclusion. ${ }^{55}$

Discussions with villagers about their aspirations tended to turn towards issues of economic security. Another major source of concern was educational opportunities for youth. An Akha woman in her early twenties, observed that

everybody who has the opportunity would want to become well educated, so that they can have a higher income ... people who leave the village to work in Bangkok or work overseas, they have nice cars, and nice houses, and they are more successful than people who stay in the village.

Along similar lines, a Lahu man reflected,

I want my children to have an easier life, unlike their parents. I want them to have a good future, and have a good place to live. My parents didn't have the money to send me to school. Now I'm too old, but I want my children to be educated.

Through engaging in acts demonstrating Buddhist identity, such as almsgiving, villagers are able to participate in the development programmes operated by the monastery, thereby gaining access to potential avenues to fulfilling some of their aspirations, such as educational opportunities for youths or agricultural development support. Yet, while the programme's proselytising objectives are clear, the exact nature of the villagers' 'conversion' to Buddhism, or their views on integration, assimilation, and loyalty to the Thai nation, are not as straightforward. When the topic of Buddhism did come up, there was typically little talk relating to topics such as attaining a favourable rebirth, the achievement of enlightenment, or other core aspects of Buddhist belief and practice. As a Lahu woman responded, 'If you ask me whether

54 Charles Keyes, 'Political crisis and militant Buddhism in contemporary Thailand', in Religion and legitimation of power in Thailand, Laos and Burma, ed. Bardwell Smith (Chambersberg, PA: ANIMA, 1978), pp. 147-64.

55 Sakboon, 'Controlling bad drugs'. For a comparative perspective from Laos, Paul Cohen argues that within Lao state-promoted processes of 'Laoisation' or national integration and assimilation of highland ethnic minorities, opium production and use is negatively depicted as backward, primitive, and antithetical to modernisation and development. These notions were reproduced in official government and international aid agency discourses which claimed that opium cultivation and consumption were the main causes of poverty among ethnic minority communities, arguments which were not supported by Cohen's fieldwork among Akha in northern Laos; Paul T. Cohen, 'Symbolic dimensions of the antiopium campaign in Laos', Australian Journal of Anthropology 24, 2 (2013): 177-92. 
I'm a Buddhist then I'm not really. Sometimes when I have time I go to help out at the temple ... but at home I pay respect to my ancestors.' Other villagers responded of the Buddhist activities they participated in, 'I just follow along with everyone else.' Some informants felt that animist and ancestor worship practices were closer in nature to Buddhism than, for instance, Christianity, such as the Lahu man who suggested that

if people are Buddhists then they do not lose their tradition so much as Christians. If you're Christian, for example if you are sick, you ask for help from the pastor, you go to church and you pray to God. But if you're an animist, you have to do many rituals in order for the illness to go away, which is more similar to being a Buddhist.

The implication was that, for some, to participate in Buddhist practices did not necessarily entail losing one's own religious identity.

Furthermore, villagers tended to view assimilation and integration in more practical terms than nationalistic devotion and loyalty to the state. Some lamented the loss of traditional culture while simultaneously citing the benefits of being able to move freely to find work without being stopped by authorities, or being able to access educational opportunities or government-funded health care. As one woman stated,

Akha people in Thailand have lost a lot of their customs. We don't know how to follow the old traditions anymore. We can't remember what to do and there's no one to teach us anymore. There are so many things to draw us away. Before, Akha women dressed in Akha clothes, now they wear Thai clothes and short skirts, everything has changed.

At the same time, it's hard for Akha people to integrate into Thai society. Often it's an issue of education. Many people do not have ID cards, they have difficulty finding food and employment, and the hospital is very expensive if you get sick. Life would be much easier if we could get help with these things.

Notions of integration, assimilation, and nationalism were complicated by highlanders' feelings of inferiority in comparison to Thais, even when they had managed to obtain citizenship cards or some other form of official recognition, as a Yao villager pointed out: 'When Thai people look down on us we have to put up with it. We can't answer back to them. They are more highly educated than us and have more rights.'

Mary Beth Mills observes that for ethnically Lao labour migrants - who are also embedded within structures of profound economic inequality and social disadvantage in Thailand, and who often migrate from the impoverished northeastern provinces to urban centres for wage labour - practices of geographical mobility can be understood not just in economically beneficially terms, but also as symbolic performances, which express 'powerful desires for national belonging and cultural citizenship'. ${ }^{56}$ In the present case, participating in activities such as almsgiving, ordination, and muai Thai function as markers of a kind of 'cultural citizenship' that establishes the experience of inclusion and validation within the sphere of the modern Thai nation in much more than just legal terms, and includes important aspects of social identity. ${ }^{57}$

56 Mary Beth Mills, 'Thai mobilities and cultural citizenship', Critical Asian Studies 44, 1 (2012): 85-112.

57 Renato Rosaldo, 'Cultural citizenship and educational democracy', Cultural Anthropology 9, 3 (1994): 402-11; Pannadda Boonyasaranai, Prasit Leeprecha, and Mukdawan Sakboon, 'Bounded nation, mobile 
Ultimately, as Jonsson argues, through such activities as the Thammacharik programme,

highlanders have been brought into the national imagination as problem peoples who are recognisable as members of the nation only to the extent that they are recipients of the care of government agencies. But they can 'improve' by committing themselves to becoming responsible modern citizens, as ethnics, nationals, and Buddhists. ${ }^{58}$

In short, by enacting certain elements of Buddhist 'identity', villagers involved in the programme are able to negotiate for themselves a measure of recognition and access to resources that might not otherwise be forthcoming. The monastery's work on the Thai-Burmese border can be compared with the activities of the Roem Mai Gospel Rehabilitation Centre, which attempts to replace dependence on drugs with faith in God as the foundation for spiritual rebirth. Distinctly transnational in character, it signifies an alternate trajectory of belonging compared to that offered by the Thai state.

\section{Gospel rehabilitation: New lives and transnational belonging}

In a mixed Christian Akha and Yunnanese village close to Thailand's border with Laos, red lanterns denoting auspicious Chinese characters hanging from dusty roofs mark the way to the Roem Mai Gospel Rehabilitation Centre. Nondescript concrete buildings serve as clean, if rather spartan, dorms. A large, open sermon hall with numerous rows of plastic chairs takes visual prominence. The grounds of the centre, including its farms, cover around $300 \mathrm{rai}$ (480 sq $\mathrm{km}$ ) of land and has corn and rubber plantations, beehives, vegetable plots, a mushroom house, and numerous pigs. The centre is run by Pastor Chaleo and Pastor Nawaracha, a Thai-Yunnanese couple, along with four other pastors and supervisers. Some of them have been through the rehabilitation treatment themselves and have lived at the centre for years. Pastor Chaleo, a former addict, overcame his drug dependency through the gospel and felt compelled to help others on the same path.

These days, the community is comprised of the staff, 30 or 40 resident former patients who assist with the centre, approximately 10 to 20 patients in recovery at any given time, and around 120 school-aged ethnic minority children and youths who are cared for by the centre in its foster home (sathan songkhro), which provides them with food, accommodation, and educational support. The children come from backgrounds of severe poverty and hardship. Some have addicted or incarcerated parents, many of whom are undergoing rehabilitation at the centre. Others have been abandoned by their families or have suffered other forms of abuse and trauma that make it impossible for them to reside in their home villages. Most patients at the centre, and many of the children, are members of ethnic minority groups from all over Chiang Rai province. According to the pastors, a predominantly large number of these are Akha. There are also some Yunnanese patients, as well as a few Thai patients

people: Lack of citizenship and immobility in northern Thailand', paper presented at the SEATIDE seminar: Religion, citizenship, tourism and trade in the process of integration, Chiang Mai, Dec. 2014; Mills, 'Thai mobilities'; Sakboon, 'Controlling bad drugs'.

58 Jonsson, Mien relations, p. 66. 
who come from as far away as Bangkok. Most patients are men in their twenties and thirties, although there are a few women in residence, with heroin and yaba being the main substances of addiction. Most have heard about the centre through word of mouth from friends, family, and acquaintances who have attended the programmes themselves, or through one of the many Christian networks around Thailand.

The gospel rehabilitation programme is based on a minimum six-month stay, for which patients pay 3,500 baht, including all food and accommodation. This minimal fee is waived for those who cannot afford it. Most of the funding comes from evangelical Taiwanese churches, and the school and recovery programme are conducted in both Thai and Mandarin Chinese. Volunteers and congregation members from Taiwan visit regularly to help at the rehabilitation centre or teach at the school, and the pastors also travel to Taiwan themselves for further training. A stay at the centre requires abstinence from all substances: cigarettes, drugs, alcohol, and medications. Even the detoxification process is 'cold turkey' - a marked contrast to government detoxification hospitals such as Thanyarak Institute, which rely heavily on medication to ease substance-dependent patients through physical withdrawal. Instead, the only 'medicine' that the patients receive here are the prayers of the entire community (athithan), who beseech the Lord on his or her behalf for a successful progression through the harrowing withdrawal phase. It is the profound surrender to a higher power that defines the programme, in which transformation and rebirth - a life free from the bondage of addiction - comes only through the acceptance of Jesus Christ as one's saviour.

Yet, as Webb Keane points out, despite the emphasis on divine agency in Protestant theology, purposeful activity (i.e. in prayer, worship, bible study, discipline, and so forth) is a central element of Christian conversion and practice. ${ }^{59}$ Patients are a mixture of Buddhists, animists, and those who were already Christians, prior to arriving at the centre. During the time I conducted fieldwork at the centre, there was a Muslim man in residence, who was seeking treatment for alcoholism. Hence, while patients are not required to be Christians prior to arriving at the centre, they are expected to follow the faith-based programme while undergoing treatment, participating in prayer sessions (namasakan), listening to sermons (fang tet), and diligently engaging in bible study (an phi). Days start at five in the morning, and include maintenance of the centre, the school, and the farm, as well as singing, sports, and Chinese language classes. The labour serves as a form of physical rehabilitation, helping physically abused bodies become stronger. Yet, more importantly than keeping the hands occupied, the work keeps the mind busy, and away from thinking about drugs.

The long-term emotional care and support available at the Roem Mai Centre and within its Christian community are far more appealing than the clinical or boot camp-style nature of government programmes that are in existence. One 32-year-old Akha patient, named Law-a, had stayed at the centre for six months in 2014 for heroin addiction. However, he relapsed when he went back home to his village near Mae Sai. He was now planning to stay at the centre for another six months. He admitted that he felt bored in the dorms in the evenings, after the day's activities had wound down

59 Webb Keane, Christian moderns: Freedom and fetish in the mission encounter (Berkeley: University of California Press, 2007), p. 56. 
and when phones were taken away. However, he reflected that the centre was a safe place, where the pastors were kind, and he could keep his mind away from drugs. Back at home and around his usual circle of friends, this was almost impossible. Law-a observed,

I'm not strong enough to stop taking drugs on my own. Here I can get strength from the gospel and the brothers and sisters around me. They are good people and have helped me a lot with my problems. I can begin to feel like maybe it's possible that I can have a good future.

As Platz found among Karen Christians, religious conversion during a time of crisis, especially during extended sickness or psychological crisis, is a frequent occurrence. ${ }^{60}$ This was also something I found to be common amongst villagers. Many related stories about being ill or undergoing some great personal difficulty, which was alleviated after they consulted the village pastor (saiyaphiban) for help. Indeed, a number of patients had brought their wives and young children to stay with them during their time in the Roem Mai programme, something which offered an additional source of support during the recovery process. Some of those who completed the programme stayed on to help out, living in separate, more private quarters than the main dorms assigned to new patients. Importantly, recovered addicts become positive role models for the new patients, who are assigned a 'partner' for their first week of the programme. This partner orients them with the schedule, activities, and helps monitor their withdrawal. Being of service is also believed to support one's own recovery. One example is A-Pya, a 24-year-old Akha man from Chiang Rai. He had started using yaba with his friends recreationally before becoming addicted. His family took him to the centre after hearing about the programme through word of mouth. There, he had found a way to come to terms with his past:

I did a lot of bad things. I even stole from my parents. I was ashamed. And then it made me want to use drugs even more. When I came here I prayed to the Lord for forgiveness. Here I can show the others that it is possible to stay away from drugs. Now my heart is lighter.

As noted earlier, there is no requirement for patients to convert to Christianity in order to join the programme. While conversion was certainly an objective, according to one of the pastors who worked with the patients, grasping the message of the gospel was difficult for the residents in the early recovery stages, and many just tended to 'follow along' without really understanding the meanings of the teachings or the activities. While a small number of patients did become more engaged with the teachings as more time passed, most returned to their own, non-Christian religious and spiritual practices once they went back to their villages. Yet, a return to the village inevitably

60 Platz, 'Buddhism and Christianity in competition?'. Similar occurrences have been reported in the practice of becoming a spirit medium in Thailand. See: Michael Rhum, The ancestral lords: Gender, descent, and spirits in a northern Thai village (Dekalb: Centre for Southeast Asian Studies, Northern Illinois University, 1994); Rosalind C. Morris, In the place of origins: modernity and its mediums in northern Thailand (Durham, NC: Duke University Press, 2000); Andrew Johnson, 'Naming chaos: Accident, precariousness, and the spirits of wildness in urban Thai spirit cults', American Ethnologist 39, 4 (2012): 766-78. 
meant resuming life under the same impoverished conditions, as well as being surrounded once more by friends and acquaintances who were, typically, still abusing substances. In such a situation, as Chaleo and Nawaracha reflected, relapse was extremely difficult to prevent, and many patients returned to the centre for repeat treatment. $^{61}$

Contrary to the 'official' rationale of salvation being achieved through faith in the gospel, in informal conversations, the patients and pastors tended to explain recovery from addiction in terms of one's own willpower and determination. As one patient reflected, 'People who are addicts are weak. They can't withstand temptation. If you want to stop you need to decide for yourself to stop. It depends on your own heart and mind, your own willpower.' Another stated, 'No one can help you get off drugs. You have to help yourself. You have to use your determination.' This sentiment was repeated by several of the pastors, who attributed craving for drugs to emotional 'emptiness', and expressed the opinion that recovery depended on whether or not a patient truly held the desire to recover in his or her heart. Such perspectives highlight how even patients who were not truly converts or who did not entirely grasp the message of the gospel were still able to derive benefits from the treatment offered and supportive structure of the Christian community.

Frank Dikötter, Lars Laaman, and Xun Zhou observe that during the late nineteenth century, China had become 'a missionary battlefield, opium the chief enemy. The image of 300 million souls hopelessly enslaved by the "pernicious drug" represented a powerful tool in legitimising missionary activities.' ${ }^{62}$ Proselytisation was carried out by depicting opium addiction as a 'disease of the will', with faith in the gospel and Christ as the divine healer being the only possible path to salvation. ${ }^{63}$ Similar missionising activities occurred in Thailand in the aftermath of opium illegalisation in 1958, although as Kammerer pointed out in reference to the Akha, this merely resulted in Christian villages filled with relapsed addicts, and a decrease in the number of ethnic minorities converting to Christianity as a way to escape opium addiction. ${ }^{64}$

Numerous observers have also noted that Christian conversion can be seen as a way to mark out an alternate identity to that of Thai ethnicity and Buddhism. For instance, Platz argues that for the Karen, 'defining oneself as Christian means being more or less in opposition to Buddhist Thai society'. ${ }^{65}$ Haiying Li notes the similar construction of new forms of identification among the Akha in Chiang Rai, who have converted to Christianity from the traditional Akha religion. ${ }^{66}$ In a similar fashion, Christian drug rehabilitation programmes such as that offered by the Roem Mai Centre, involve creating a sense of support, community and fellowship in ways which

61 Unfortunately, the centre does not keep records of treatment retention or relapse rates or conduct formal surveys to gather this data. Therefore, it is difficult to accurately estimate the programme's success rate.

62 Dikötter, Laaman and Zhou, Narcotic culture, p. 100.

63 Ibid.

64 Kammerer, 'Customs and Christian conversion': 287.

65 Platz, 'Buddhism and Christianity in competition?': 487; see also Yoko Hayami, 'Karen tradition according to Christ or Buddha: The implications of multiple reinterpretations for a minority ethnic group in Thailand', Journal of Southeast Asian Studies 27, 2 (1996): 334-9.

66 Haiying Li, 'Neo-traditionalist movements and the practice of Aqkaqzanr in a multi-religious community in northern Thailand' (Master's thesis, Chiang Mai University, 2013). 
are mediated not by the Thai state, but rather, through missionary projects that emphasise belonging within a transnational spiritual Christian community.

\section{Conclusion}

The Thai state's exclusionary policies towards ethnic minorities play a significant role in exacerbating the very issues of national integration and border security that it is attempting to tackle. In a scenario that shares many parallels with the situation in Thailand, in the midst of prohibition campaigns during the late nineteenth to midtwentieth century in China:

[The] 'war on drugs' allowed political leaders and social elites to invent a fictive enemy on to whom social anxieties could be projected: narcophobia created a scapegoat ... opium became the rallying point around which social unity could be asserted, as both addicts and imperialists emerged as the ultimate alter ego against which national identity could be defined. ${ }^{67}$

The Thai government's opium eradication campaigns and exclusionary citizenship policies have not only appeared to worsen rather than improve socioeconomic conditions for ethnic minorities - they have also contributed to constructing a border security problem resulting from the regional 'drug threat', as well as a politicallydisloyal, criminally-minded, drug-addicted 'hill tribe' subject against which Thai national identity can be defined. In another paradox, this process has provided the impetus for alternate modes of transnational belonging to emerge in the form of gospel rehabilitation and widespread Christian conversion among ethnic minorities, in response to the marginalisation engendered by state policies.

Alternative development and crop substitution strategies have been lauded triumphantly, presenting Thailand as a regional and international model of opium eradication success. ${ }^{68}$ In reality, these strategies have failed to improve the livelihoods of the majority of highland people in Thailand: opportunities are provided for a few individuals and communities while the remainder are excluded from the global trajectory of modernisation and development. From certain perspectives, opium substitution initiatives appear to have actually exacerbated and given new forms to the drug problem, by creating the need for labourers to consume methamphetamines in order to perform at the required level in order to survive economically. Furthermore, while there has been a great deal of discussion in recent years about inequality in Thailand stemming from the ongoing political crisis, this dialogue seldom, if ever, includes a discussion of ethnic minorities, which are among the most disadvantaged populations in the country and which arguably have the lowest status of all the highlanders dispersed across the Southeast Asian Massif.

Not least, the development programmes' limitations lie in their inability to address the long history of ethnic tensions, violent conflicts, and political profiteering from the drug trade in the region, which comprise some of the root causes of the issue. It is undeniable that 'drug use among highland populations emerges from

67 Dïkotter, Laamann and Zhou, Narcotic culture, pp. 93-4.

68 UNODC, Alternative development. 
the constant intersection of poverty and lack of access to services'. ${ }^{69}$ However, it would be a fallacy to assume that the success of development programmes would solve the region's drug problem. As Chouvy, referring to the world's two main sites for illegal drug production, argues, 'economic development, whether in rural or urban areas, can only occur in countries and regions where peace prevails and is sustainable ... until the conflicts and political crises of Afghanistan and Myanmar have been solved all anti-drug efforts will most likely be in vain'. ${ }^{70}$

Ultimately, in their emphases on individual psychology and morality, the Roem Mai Centre and the Golden Horse Monastery frame addiction and poverty in terms of personal failure, rather than as interconnected social, political and economic problems. Religious conversion in both the examples presented here expresses goals of inclusion and belonging. At the same time, I am not suggesting that Christian or Buddhist conversion represents a simple way for ethnic minority individuals to escape marginalised situations. As mentioned earlier, for ex-patients of the gospel rehabilitation centre, relapse is extremely common upon returning to the village. For villagers involved in the monastery's programmes, aspirations are circumscribed by a combination of structural factors, including the lack of opportunities, and negative stereotypes of and pervasive discrimination against ethnic minorities, which continue to form the bases for exclusion - even as the state capitalises on 'hill tribe culture' as the lucrative cornerstone of northern Thai tourism.

Comparative research on similar phenomena in other highland Southeast Asian contexts is needed in order to provide a more comprehensive understanding of this issue and to build a more nuanced theoretical framework in which the usefulness of the concept of Zomia rests not so much in its definition as a physical space or object of inquiry, but in its utility as a 'site for the production of knowledge'; a set of theoretical problematics 'whose starting hypothesis would be the fundamental complexity, instability, and permeability of sociocultural systems to permeable influences' ${ }^{71}$ Such research would also shed more light on the relationship between highland peoples and nationstates, and between highland peoples across nation-states, in a manner which recognises that the issue is more complex than the juxtaposition between the 'non-state' space of Zomia and the 'state space' of the dominant authority. It is an ambiguous social location that entails neither full incorporation nor exclusion, but rather, intricate dynamics of aspiration, belonging, and negotiation.

69 Lyttleton, 'Relative pleasures': 920.

70 Chouvy, Opium, p. 201.

71 Formoso, 'Zomian or zombies?': 316, 332. 